\title{
Age-related grey matter volume correlates of response inhibition and shifting in attention- deficit hyperactivity disorder
}

Grainne M. McAlonan, Vinci Cheung, Siew E. Chua, Jaap Oosterlaan, Se-fong Hung, Chun-pan Tang, Chi-chiu Lee, Shi-leung Kwong, Ting-pong Ho, Charlton Cheung, John Suckling and Patrick W. L. Leung

\section{Background}

Children with attention-deficit hyperactivity disorder (ADHD) have difficulties with executive function and impulse control which may improve with age.

\section{Aims}

To map the brain correlates of executive function in ADHD and determine age-related changes in reaction times and brain volumes.

\section{Method}

Attention-deficit hyperactivity disorder and control groups were compared on the change task measures of response inhibition (stop signal reaction time, SSRT) and shifting (change response reaction time, CRRT). Voxel-wise magnetic resonance imaging (MRI) correlations of reaction times and grey matter volume were determined, along with bivariate correlations of reaction times, brain volumes and age.

\section{Results}

Individuals in the ADHD group had longer SSRTS and CRRTS. Anterior cingulate, striatal and medial temporal volumes highly correlated with SSRT. Striatal and cerebellar volumes strongly correlated with CRRT. Older children had faster reaction times and larger regional brain volumes. In controls, orbitofrontal, medial temporal and cerebellar volumes correlated with CRRT but not SSRT. Neither reaction times nor regional brain volumes were strongly agedependent.

\section{Conclusions}

Our evidence supports delayed brain maturation in ADHD and implies that some features of ADHD improve with age.

\section{Declaration of Interest}

None. Funding detailed in Acknowledgements.
Children with attention-deficit hyperactivity disorder (ADHD) are impaired in a well-validated test of response inhibition known as the 'stop' signal task. ${ }^{1,2}$ In an extension of the stop task, the 'change' task, the participant must inhibit a prepotent response tendency and quickly shift to another response, i.e. response re-engagement. ${ }^{3}$ Thus, the executive function demands of the change task are greater than the stop task, and the stop signal reaction time (SSRT) and change response reaction time (CRRT) indices are considered sensitive measures of inhibitory control and response re-engagement respectively. ${ }^{3}$ It has been proposed that abnormalities in a prefrontal-striatal-posterior parietal 'attention system' of the brain ${ }^{4}$ account for this and other core symptoms of ADHD. However, in a recent large scale, longitudinal analysis detailing cortical thickness in ADHD, Shaw et al provided evidence that the pattern of brain maturation in ADHD was delayed, rather than abnormal. In the present study we used voxel-based structural magnetic resonance imaging (MRI) analyses to test a predicted link between SSRT and CRRT and fronto-striatal volumes in children with ADHD. Since symptoms of impulse control improve with age in $\mathrm{ADHD}^{6}$ and the stop signal reaction task is known to be sensitive to developmental changes in performance, ${ }^{7}$ we also expected that delayed maturation in ADHD would be reflected by faster reaction times and larger regional brain volumes in older children.

\section{Method}

\section{Participants}

The study was approved by the local hospital institutional review board. Participants were 51 male Hong Kong Chinese children (22 with ADHD and 29 typically developing) aged between 6 and 12 years who had been recruited for a voxel-based group comparison
MRI study published previously. ${ }^{8}$ All the children attended local mainstream schools and had a verbal IQ above 80 (estimated on the verbal subset of the Weschler Intelligence Scale for Children, $($ WISC-III $))^{9}$ (Table 1). Diagnostic status was confirmed for all participants using the parental Chinese Diagnostic Interview Schedule for Children for DSM-IV. ${ }^{10}$ No child had a significant medical condition affecting brain function (e.g. epilepsy) or history of head injury. All but three (newly diagnosed) children with ADHD were considered by their case doctors to be responsive to methylphenidate.

\section{Cognitive testing}

Children taking methylphenidate were asked to stop taking their medication $48 \mathrm{~h}$ prior to testing. Participants were tested on an extended version of the stop task - the change task. ${ }^{3}$ In the change task, the stop signal prompts both response inhibition and re-engagement which can be measured by two performance indices (i.e. SSRT and CRRT). In brief, 75\% of trials in the task were 'go' trials; participants had to locate an aircraft presented on the left or right of a computer screen and use their left hand to press the corresponding left or right response button with middle or index fingers respectively. Twenty-five per cent of trials were stop trials presented pseudo-randomly. In response to an auditory signal in stop trials, participants had to inhibit their response and immediately press a third button with their right thumb (the change response). A lengthened SSRT is thought to reflect impaired inhibitory control and is derived from the 'inhibition function', generated by plotting the probability of inhibition against the range of stop signal intervals and correcting for non-responses, as previously reported. ${ }^{11}$ The rationale behind this correction is that non-responses may occur on stop trials, thereby increasing the probability of inhibition. The CRRT is 
the time taken to shift to a new response using the right thumb. A lengthened reaction time suggests inefficient response re-engagement, i.e. difficulty shifting to a new response.

We used independent $t$-tests in SPSS (version 15.0 for Windows) to examine group differences in SSRT and CRRT. In addition, although the groups were balanced for age, we also examined the relationship of age to reaction time indices for each group separately in bivariate correlation analyses. Between-group differences in age-related performance were investigated by transforming Pearson $r$ 's into Fisher $z$-scores to test the significance of the difference between correlations. ${ }^{12}$

\section{MRI acquisition and analyses}

Three millimetre slice thickness, dual-echo fast spin echo data-sets aligned to the anterior- posterior commissural (AC-PC) line were acquired across the whole brain on a GE signa $1.5 \mathrm{~T}$ system (General Electric, Milwaukee, Wisconsin, USA). Pre-processing of the images followed methods previously described in a group comparison study which included the majority of these children. ${ }^{6}$ That is, images were segmented by setting voxels representing extracerebral tissue to zero and probability of each intracerebral voxel belonging to grey matter, white matter, cerebrospinal fluid or dura/vasculature tissue classes was calculated. Knowing the voxel size $\left(2.2 \mathrm{~mm}^{3}\right)$, the volume of any tissue class could be estimated at each voxel and summed across all intracerebral voxels to yield global tissue class volumes. The segmented grey matter images were mapped onto standard space by minimising the sum of square intensity difference of each proton density image to a group-specific template ${ }^{6}$ and smoothed with a $4.4 \mathrm{~mm}$ kernel. Simple linear regression of reaction time indices with grey matter volume at each intracerebral voxel was carried out using BAMM software (Brain Analysis Morphological Mapping version 2.5,
Cambridge University) for each group separately. Regions of significant correlation were identified in two stages by permutation test. Initially, a voxel-wise probabilistic threshold was applied to generate three-dimensional clusters characterised by their mass, or the sum of suprathreshold voxel statistics it comprised. Clusters were then subject to a non-parametric analysis by randomly generating 10 permutated maps to sample the null hypothesis that significant correlations occur by chance. The statistical thresholds were corrected for multiple comparisons by controlling the 'family wise error rate' expected such that the number of false positive tests for each map was less than 1 false positive cluster. We also examined the bivariate correlations of age with the brain volumes derived from the voxel-based analysis in each group using SPSS 15.0 for Windows.

\section{Results}

\section{Change task performance}

Children with ADHD made more errors than children in the control group. Despite having similar reaction times to controls on go trials, their reaction times were more variable, as indicated by their significantly greater reaction time standard deviations. We also confirmed a significantly slower SSRT and CRRT in this sample of children with ADHD compared with typically developing controls (Table 1). Older children with ADHD had faster reaction times than younger children (SSRT: age $r=-0.45$, $P=0.04$; CRRT: age $r=-0.56, P=0.007$ ). As shown in Fig. 1, children with ADHD had similar reaction times to controls at a later age, and tended to 'catch-up' with controls by 12 years. Age did not strongly correlate with SSRT in the control group $(r=-0.33, P=0.11)$; the correlation of age with CRRT in the control group just failed to reach significance $(r=-0.39$, $P=0.054)$. However, the group difference between the correlation

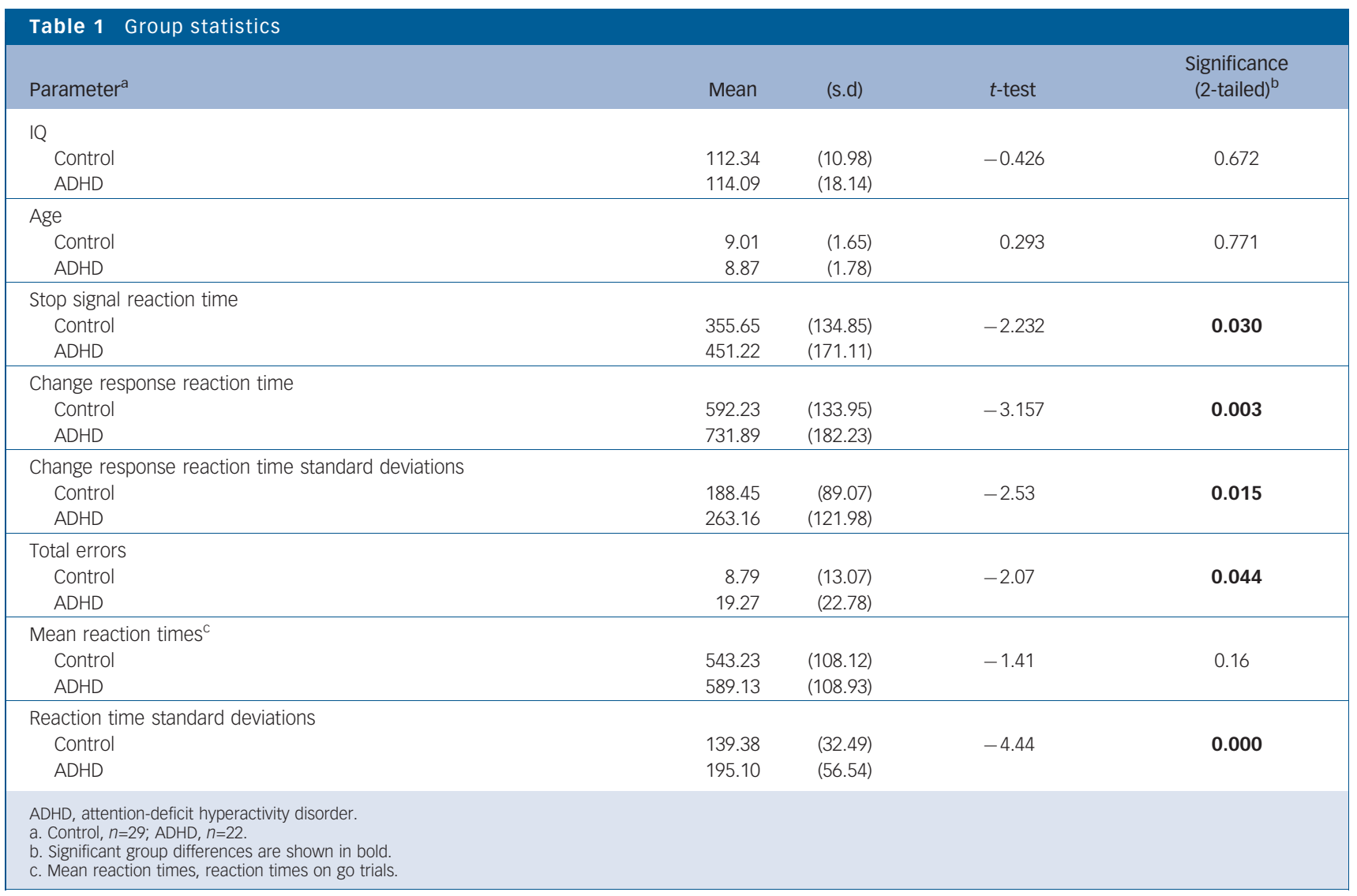



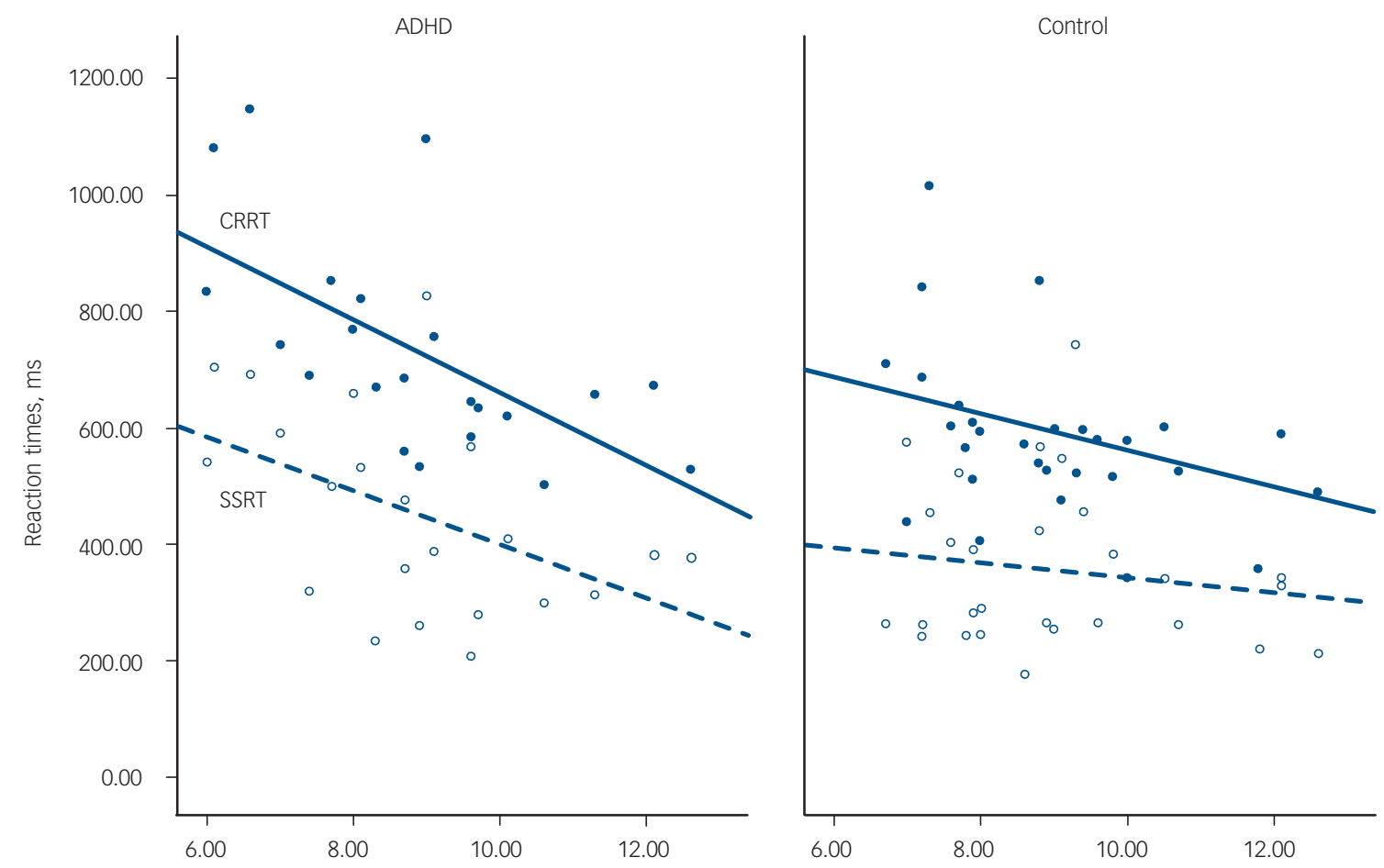

Fig. 1 Age-related changes to reaction times.

ADHD, attention-deficit hyperactivity disorder; CRRT, change response reaction time in closed circles and solid line; SSRT, stop signal reaction time in open circles and dashed line.

coefficients for SSRT or CRRT was not significant $\left(z_{\mathrm{obs}}=0.45\right.$ and $z_{\text {obs }}=0.80$ respectively).

\section{MRI reaction time correlates}

In the ADHD group, two scans with movement artifact were excluded. In the control group, four children refused a scan; one scan with movement artifact was excluded. Therefore, scans from 20 children with ADHD and 24 controls entered analyses.

\section{Grey matter correlates of SSRT}

\section{Attention-deficit hyperactivity disorder}

There was a significant negative correlation between SSRT and the volume of grey matter clusters in the anterior cingulate, right lentiform nucleus and the left medial temporal lobe (involving amygdala, hippocampus and parahippocampal regions) in children with ADHD (false positive clusters $<1$, cluster test significance $P=0.001$; Fig. 1 and Table 2). Thus, better/faster inhibition was associated with greater grey matter volumes in these regions in those with ADHD. Grey matter regions correlated with SSRT showed significant positive intercorrelations (Table 2). Eightynine per cent of the variance in SSRT was jointly explained by these volumes $\left(r=-0.94, P<0.001, \mathrm{R}^{2}=0.887\right)$. Age was significantly positively correlated with regional grey matter volumes, but not total grey matter volumes. Thus older children, who had larger regional brain volumes in temporal-pallidal-anterior cingulate, had faster SSRT (Fig. 2).

\section{Controls}

No regional volumes were correlated with SSRT in the control group. Age was not correlated with SSRT in the control group $(r=-0.33, P=0.11)$.

\section{Grey matter correlates of CRRT}

\section{Attention-deficit hyperactivity disorder}

Negative correlations between regional brain volumes and CRRT in the ADHD group involved the right lentiform nucleus and left cerebellum (false positive clusters $<1$, cluster test significance $P=0.001$; Fig. 2 and Table 3). Again, larger regional volumes were linked with faster reaction times (Table 2). The volume of the cerebellar cluster and basal ganglia clusters correlated with CRRT also showed a significant positive intercorrelation (Table 3). Approximately $75 \%$ of the variance in CRRT was jointly explained by these volumes ( $\left.r=-0.87, P<0.001, \mathrm{R}^{2}=0.75\right)$. Age was significantly correlated with these volumes, but not total grey matter volume as shown in Table 2. Thus, older children with larger regional brain volumes in basal ganglia and cerebellum had faster CRRT (Fig. 2).

\section{Controls}

The volume of grey matter clusters in ventral prefrontal cortex, right medial temporal lobe and cerebellum (midline and left hemisphere) was negatively correlated with CRRT (false positive clusters $<1$, cluster test significance $P=0.001$; Fig. 2 and Table 4). Thus, larger regional volumes were linked with faster reaction times. These grey matter volumes showed significant positive intercorrelations (Table 4). Seventy-seven per cent of the variance in CRRT in controls was jointly explained by these volumes $\left(r=-0.88, \quad P<0.001, \mathrm{R}^{2}=0.77\right)$. Age did not correlate with regional brain volumes.

\section{Supplementary analysis}

To control for the confounding effect of age on regional brain volume we ran a partial correlation analysis on regional volumes and reaction times with age controlled. For all children, controls and those with $\mathrm{ADHD}$, the highly significant correlation between 
Table 2 Correlates of reaction times in participants with attention-deficit hyperactivity disorder ${ }^{2}$

\begin{tabular}{|c|c|c|c|c|c|}
\hline ADHD and SSRT, $n=20$ & $\begin{array}{c}\text { Temporal } \\
-28.80 .122 .6 \\
\text { BA } 34,35,38 \\
\text { Voxels }=449\end{array}$ & $\begin{array}{c}\text { Putamen } \\
30.1-3.05 .5 \\
\text { Voxels }=539\end{array}$ & $\begin{array}{c}\text { Cingulate } \\
1.89 .630 .9 \\
\text { BA } 8,21,24,32 \\
\text { Voxels }=660\end{array}$ & Total grey & SSRT \\
\hline Putamen & $0.800^{* *}$ & & & & \\
\hline Cingulate & $0.823^{* *}$ & $0.876^{* \star}$ & & & \\
\hline SSRT & $-0.844^{\star *}$ & $-0.839 * *$ & & & \\
\hline Total grey & 0.061 & 0.327 & & & \\
\hline SSRT & $-0.844^{* *}$ & $-0.839 * *$ & $-0.959 * *$ & -0.199 & \\
\hline Age & 0.376 & $0.603^{* *}$ & $0.472^{\star}$ & -0.157 & $-0.451^{*}$ \\
\hline
\end{tabular}

Table 3 Correlates of reaction times in participants with attention-deficit hyperactivity disorder ${ }^{a}$

\begin{tabular}{|c|c|c|c|c|}
\hline ADHD and CRRT, $n=20$ & $\begin{array}{c}\text { Cerebellum } \\
-34.1-62.5-22.1 \\
\text { Voxels }=723\end{array}$ & $\begin{array}{c}\text { Striatum } \\
28.0-4.96 .0 \\
\text { Voxels }=460\end{array}$ & Total grey & CRRT \\
\hline Striatum & $0.682 * *$ & & & \\
\hline Total grey & 0.238 & 0.227 & & \\
\hline CRRT & $-0.815^{\star *}$ & $-0.798^{* *}$ & -0.131 & \\
\hline Age & $0.498^{*}$ & $0.715^{* *}$ & -0.157 & $-0.587^{* *}$ \\
\hline
\end{tabular}

regional brain volume and reaction time was preserved. The minimum Pearson $r=0.53, P<0.01$.

\section{Discussion}

Consistent with previous reports, ${ }^{1,2}$ the ADHD group performed more poorly than age and IQ-matched typically developing controls in the change task. They had difficulty inhibiting a prepotent response (longer SSRTs) and took longer to shift to a new response (CRRT). These reaction times were very highly correlated with fronto-striatal-temporal volumes. The volumes increased with age, and older children with ADHD had faster reaction times than younger children. Specifically, more efficient inhibitory control was linked to larger regional grey matter volumes in bilateral anterior cingulate, right basal ganglia and left medial temporal circuitry in ADHD. Faster response re-engagement was linked to larger regional grey matter volumes in striatum and the left cerebellum. In the control group SSRT was not linked to regional grey matter volumes. Faster CRRT was associated with greater volumes in ventral prefrontal cortex, right medial temporal lobe and cerebellar regions. Although reaction time indices did tend to improve with age in the control group, the size of brain regions correlated with these indices did not increase with age.

Taken together, these observations suggest an important agerelated improvement in reaction time indices in ADHD parallel to an age-related increase volume across a specific striatal grey matter circuitry. This is consistent with recent evidence that the brain, especially the frontal lobe, matures late in ADHD. ${ }^{5}$ It is important to note that the present study was not designed to investigate brain volume abnormalities in ADHD, only volumereaction time correlates. However, in our previous study of brain structure in ADHD, which incorporated many of the same children, we did find significantly lower volumes in striatal regions in children with ADHD that overlapped with the regions reported to be linked to reaction times here. ${ }^{8}$ In addition, others have reported that the dorsal anterior cingulate, right lentiform nucleus, ${ }^{13-15}$ medial temporal lobe ${ }^{16}$ and cerebellar regions ${ }^{17}$ are smaller in ADHD, and the dorsal anterior cingulate has also been consistently shown to have activation deficits during functional imaging studies of the stop task. ${ }^{18-22}$

Associations between right-sided frontostriatal volumes and response inhibition have previously been reported in a regionof-interest study of ADHD. ${ }^{23}$ In their study, Casey et al ${ }^{23}$ investigated three different response inhibition tasks. However, only one component of the range of attention tasks examined is in some way comparable to the SSRT measure of inhibition examined here, namely the reaction time in go/no-go 'response execution' inhibitory trials. Interestingly, Casey's group found a significant positive correlation between left globus pallidus volume and mean reaction time in control boys, but not boys with ADHD. ${ }^{23}$ In contrast, in our whole brain grey matter voxel-wise analyses we found the SSRT was very strongly correlated with a prefrontaltemporal-right pallidal circuit in boys with ADHD and not controls. Thus task differences, as well as very different approaches to analysis, may contribute to the discrepancy between the studies.

Our findings of bilateral frontal correlations of impaired inhibitory control in ADHD deviate from those of an elegant series of studies comparing inhibitory dysfunction after right frontal lesions to dysfunction in ADHD. ${ }^{24-26}$ These authors emphasised right lateralised frontal involvement in this function. However, both studies implicated the right striatum. Disentangling the direct effects of a lesion from the indirect or compensatory actions of intact brain structures is a challenge which can complicate interpretation of lesion studies. The voxel-based approach adopted here has the advantage of exploring potential whole brain grey matter correlates of inhibitory control in ADHD directly, and may explain why our results do not completely coincide with lesion studies.

The choice of the change task rather than the stop signal task, meant that additional demands upon executive function, in terms 
(a)

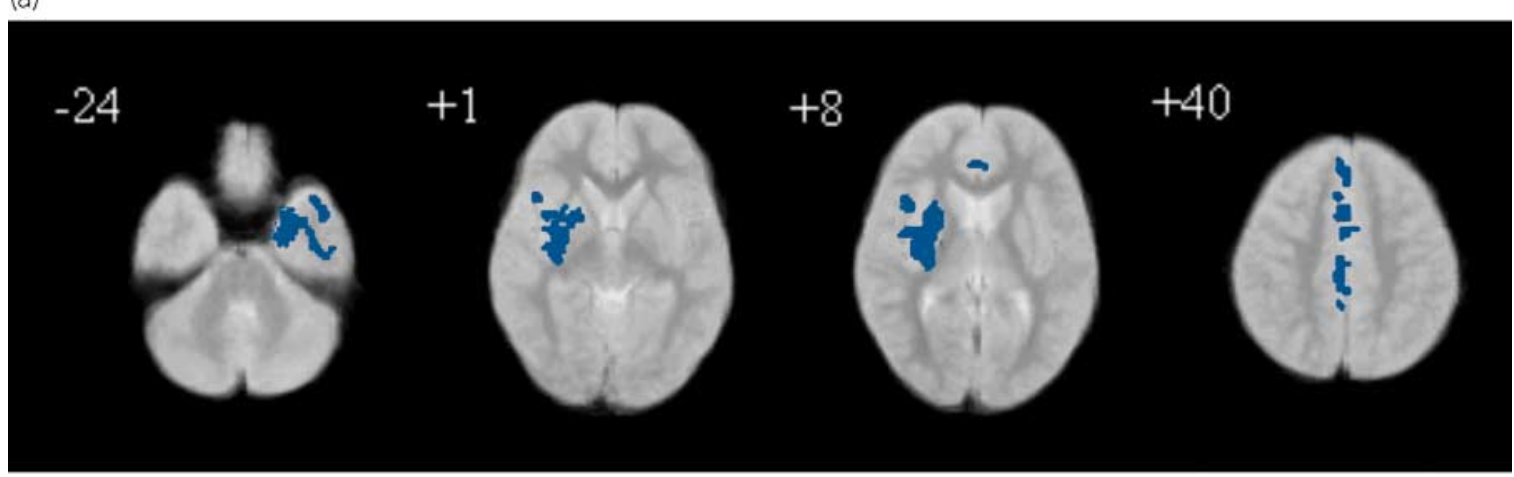

(b)

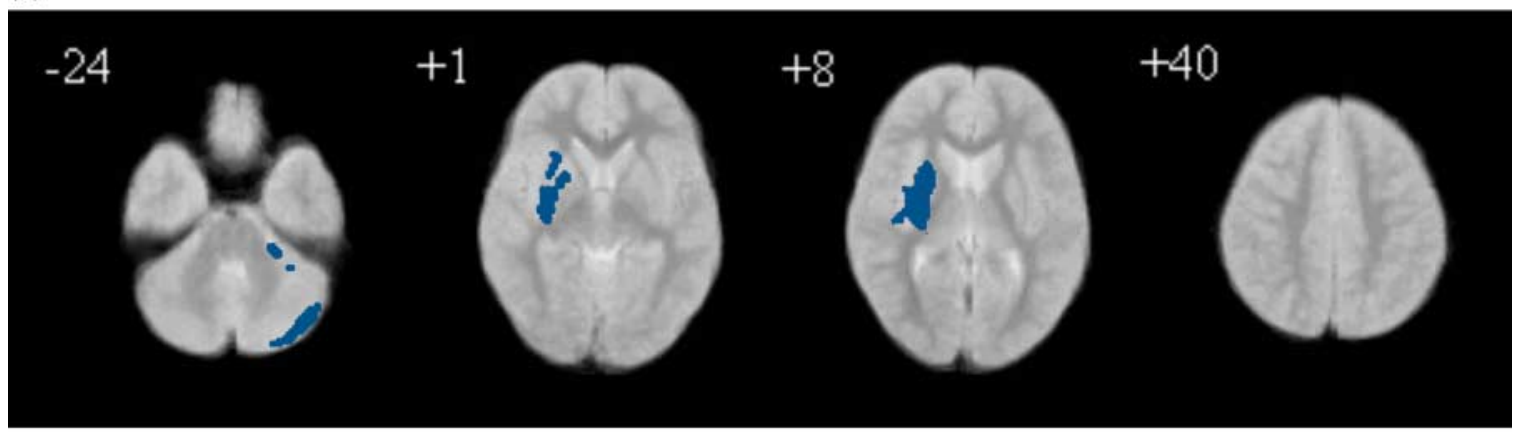

(C)

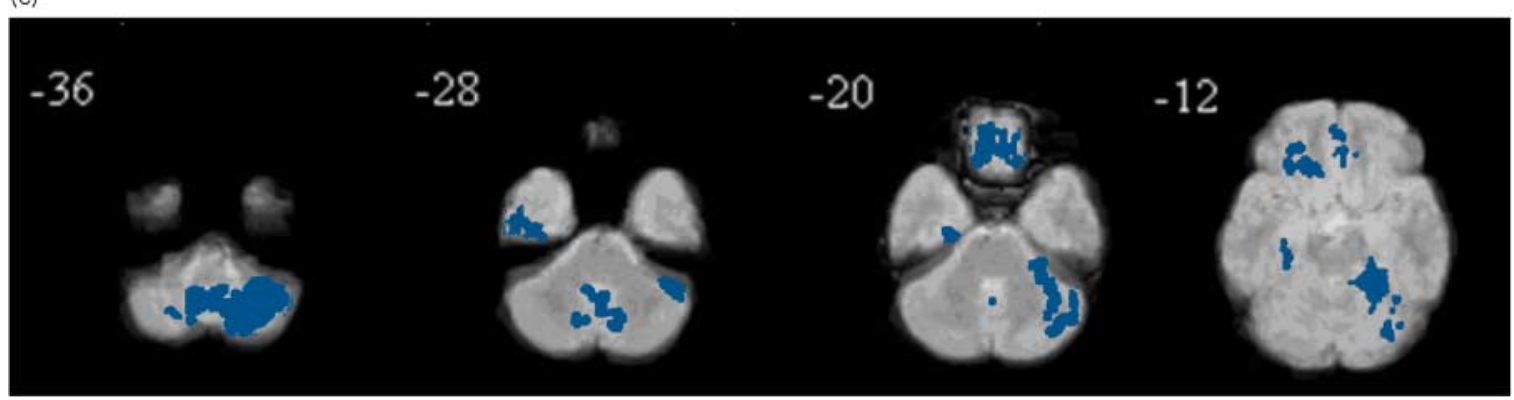

Fig. 2 Regional brain volume correlates of reaction time indices.

(a) Stop signal reaction time correlates in attention-deficit hyperactivity disorder (ADHD); (b) change response reaction time (CRRT) correlates in ADHD; (c) CRRT correlates in controls. Blue clusters: negative correlation (false positive clusters $<1, P=0.001$ ). Left side of brain is on the right of the panel ( $z$-coordinates shown).

of response re-engagement, could be addressed. We found the volume of the right basal ganglia linked to both inhibition and response shifting ability in ADHD. The demands of response re-engagement were also correlated with left cerebellar volume in ADHD. In the control group, this reaction time index was strongly correlated with cerebellar volumes. The implication, that the cerebellum is important for response shifting, fits growing recognition of its interaction with the prefrontal lobe to affect higher order cognitive processing. ${ }^{27,28}$ Indeed CRRT in the control group was also correlated with volumes in the ventral prefrontal cortex.

\begin{tabular}{|c|c|c|c|c|c|c|c|}
\hline $\begin{array}{l}\text { Control and CRRT } \\
(n=24)\end{array}$ & $\begin{array}{c}\text { Vermis } \\
-9.2-57.3-34.8 \\
\text { Voxels }=772\end{array}$ & $\begin{array}{c}\text { Temporal } \\
36.8-12.4-24.0 \\
\text { BA 20, 21, 38, 36 } \\
\text { Voxels }=215\end{array}$ & $\begin{array}{c}\text { Cerebellum } \\
-37.1-58.0-20.7 \\
\text { Voxels }=177\end{array}$ & $\begin{array}{c}\text { Cerebellum } \\
-23.2-41.4-14.2 \\
\text { Voxels }=257\end{array}$ & $\begin{array}{c}\text { Prefrontal } \\
4.535 .7-15.7 \\
\text { BA 11, } 32 \\
\text { Voxels }=435\end{array}$ & $\begin{array}{l}\text { Total } \\
\text { grey }\end{array}$ & CRRT \\
\hline Temporal & 0.896 ** & & & & & & \\
\hline Cerebellum & $0.806 * *$ & $0.787 * *$ & & & & & \\
\hline Cerebellum & 0.930 ** & $0.899 * *$ & $0.899 * *$ & & & & \\
\hline Prefrontal & $0.889 * *$ & 0.926 ** & 0.778 ** & $0.889 * *$ & & & \\
\hline Total grey & $0.428^{\star}$ & $0.434^{\star}$ & 0.290 & $0.456^{\star}$ & $0.460 *$ & & \\
\hline CRRT & $-0.836^{* *}$ & $-0.860 * *$ & $-0.801 * *$ & $-0.835^{* *}$ & $-0.875^{* *}$ & -0.207 & \\
\hline Age & 0.253 & 0.196 & 0.373 & 0.317 & 0.265 & -0.347 & -0.398 \\
\hline
\end{tabular}


We expected to find prefrontal cortex volumes correlated with CRRT in the ADHD group. Therefore, since the variance in CRRT accounted for jointly by the volumes of clusters in the right basal ganglia and left cerebellum was modest at $75 \%$, we relaxed the statistical thresholding to allow $<2$ false positive clusters at $P<0.002$. In this analysis we found significant clusters in anterior cingulate and right medial temporal lobe were also associated with time taken to shift response. When subsequently added, these volumes together explained approximately $83 \%$ of the variance in CRRT $\left(r=-0.91, P<0.001, \mathrm{R}^{2}=0.83\right)$. Thus, the correlates of inhibition and choice reaction times appear to involve a similar neural system in ADHD. Interestingly, studies of other populations with neurodevelopmental difficulties agree that a selective network incorporating the cerebellum, ${ }^{29}$ right basal ganglia $^{29,30}$ and cingulate ${ }^{29,31}$ appears important for inhibitory processes.

The present study implicates the medial temporal lobe in inhibitory control in ADHD. Disinhibition may theoretically arise from disruption to a motivational limbic-based system. $^{32,33}$ In this conceptualisation, motivational anomalies in children with ADHD result in inappropriate behaviour. Animal models support a key role for hippocampal areas in a 'behavioural inhibition system' which normally interrupts ongoing activity when an expected reward is not evident, or when a signal for punishment is detected. ${ }^{34}$ This model has been applied to children with $\mathrm{ADHD}^{35}$ who appear to have an altered sensitivity to reward contingencies. ${ }^{36,37}$ Thus, our finding that inhibitory control in children with ADHD is associated with the volume of both frontal (anterior cingulate) grey matter and the amygdala/hippocampal complex is exciting. It fits with recent evidence that the anterior cingulate in humans is essential for integrating information about reward and directing decision-making. ${ }^{38,39}$ Of note, unlike for the striatum and cingulate, age did not strongly correlate with temporal volumes in the ADHD group. This may point to some rather more fixed impact of temporal lobe structure. It will be interesting to manipulate reward contingencies in future studies to explore how motivational variables might have contributed to the present result.

Age-related changes in grey matter in ADHD were not global and only regional, not total, grey matter volumes showed significant age-related increase. Thus, there appeared to be a dissociation of global grey matter volumes and the striatal network implicated here in ADHD. We speculate that this may have something to do with an altered pattern of maturation in ADHD. Indeed, the regional brain volumes implicated in reaction timing in ADHD did not correlate with total grey matter volumes. In contrast, regional grey matter volumes associated with CRRT in the control group did generally correlate with total grey matter volume. We postulate that a delay in grey matter maturation in a restricted striatal network in ADHD might render this circuit 'out-of-step' with overall whole brain development. We identified strong positive volumetric correlations between prefrontal cortex, basal ganglia and medial temporal lobe linked to reaction time indices in ADHD. Such intercorrelations are thought to reflect connectivity $^{40}$ as interconnecting systems share common developmental and maturation influences. The present anatomical pattern is consistent with known direct projections between the anterior cingulate and amygdala/hippocampus and indirect connections via the basal ganglia. ${ }^{41}$ Moreover, a genetic 'dopamine-deficit' in this mesolimbic-cortical network, especially the $\mathrm{D}_{4}$-rich frontal lobes, has been postulated in ADHD. ${ }^{42}$ Taken together, the evidence suggests that executive dysfunction in ADHD depends upon maturation of a restricted dopaminergic frontostriatal network.

\section{Limitations}

Our study has a number of limitations. We documented the relationship between functional indices, brain volume and age in children less than 12 years old, i.e. likely to be prepubertal. Cortical grey matter volumes begin to decrease from the age of 12 years, with prefrontal lobe volume reduction happening last in sequence. ${ }^{43}$ Thus, it will be important to establish how neuropsychological function and brain morphology are affected by ADHD in an older age group. Our study was cross-sectional, therefore we can only comment on age-related findings. Clearly further longitudinal studies are needed to properly address the issue of brain maturation delay in ADHD. This would be particularly important in those few individuals with ADHD in whom regional brain volumes were markedly lower and reaction times longer than children of a similar age. It is possible that deviations from the age-dependent pattern observed here have implications for prognosis.

With the exception of three newly diagnosed children, the participants in our study were considered to be responsive to stimulant medication. Therefore we cannot say whether the results apply to children with ADHD who do not respond to medication. Moreover, we did not have detailed information about the treatment protocol followed by these boys, so we cannot be certain what effect drug treatment had on the results. Although medication does not appear to grossly alter brain structure in $\mathrm{ADHD},{ }^{44}$ evidence from a recent positron emission tomography study suggests that the degree of inattention and impulsivity in adolescents with ADHD is linked with dopamine receptor sensitivity to medication. ${ }^{45}$ The interaction of brain, behaviour and medication needs closer examination and will be a focus of further studies. Lastly, our work focused solely on male children with ADHD and we do not know to what extent our observations generalise to females and adults with ADHD. Future work is planned to address these issues.

Our study illustrates the use of voxel-based methods to explore the brain morphology underlying complex behavioural indices affected by ADHD and should encourage its wider application. The results link grey matter volume of a discrete prefrontal-pallidal-temporal circuit to executive performance in ADHD. In older children with ADHD the volume of this circuitry is greater and their reaction times are faster. This has the welcome implication that some features of ADHD may improve with age.

Grainne M. McAlonan, PhD, State Key Laboratory for Brain and Cognitive Sciences and Department of Psychiatry, University of Hong Kong; Vinci Cheung, PhD, Department of Psychiatry, University of Hong Kong; Siew E. Chua, MRCPsych, State Key Laboratory for Brain and Cognitive Sciences and Department of Psychiatry, University of Hong Kong People's Republic of China: Jaap Oosterlaan. PhD, Department of Clinical Neuropsychology, Vrije University, Amsterdam, The Netherlands; Se-fong Hung, FRCPsych, Chun-pan Tang, MRCPsych, Chi-chiu Lee Netherlands; Se-fong Hung, FRCPSych, Chun-pan Tang, MRCPSych, Chi-chiu Lee
MRCPsych, Shi-leung Kwong, FHKCPSych, Department of Psychiatry, Kwai Chung Hospital, Hong Kong; Ting-pong Ho, MD, Charlton Cheung, PhD, Department of Psychiatry, University of Hong Kong, People's Republic of China; John Suckling, PhD, Cambridge Brain Mapping Unit, Department of Psychiatry, University of Cambridge, UK; Patrick W. L. Leung, PhD, Department of Psychology, Chinese University of Hong Kong, People's Republic of China.

Correspondence: Grainne M. McAlonan, Department of Psychiatry, University of Hong Kong, Pokfulam, Hong Kong. Email: mcalonan@hkucc.hku.hk

First received 18 Feb 2008, final revision 22 Jun 2008, accepted 10 Jul 2008

\section{Acknowledgements}

This study was supported by a University of Hong Kong Grant to S.E.C. The authors would like to thank Ms Michelle Deng for her help with figure preparation. 


\section{References}

1 Oosterlaan J, Logan GD, Sergeant JA. Response inhibition in $A D / H D, C D$, comorbid $A D / H D+C D$, anxious, and control children: a meta-analysis of studies with the stop task. J Child Psychol Psychiatry 1998; 39: 411-25.

2 Lijfijt M, Kenemans JL, Verbaten MN, van Engeland $\mathrm{H}$. A meta-analytic review of stopping performance in attention-deficit/hyperactivity disorder: deficient inhibitory motor control? J Abnorm Psychol 2005; 114: 216-22.

3 Oosterlaan J, Sergeant JA. Response inhibition and response re-engagement in attention-deficit/hyperactivity disorder, disruptive, anxious and normal children. Behav Brain Res 1998; 94: 33-43.

4 Berger A, Posner MI. Pathologies of brain attentional networks. Neurosci Biobehav Rev 2000; 24: 3-5.

5 Shaw P, Eckstrand K, Sharp W, Blumenthal J, Lerch JP, Greenstein D, Clasen L, Evans A, Giedd J, Rapoport JL. Attention-deficit/hyperactivity disorder is characterized by a delay in cortical maturation. Proc Natl Acad Sci USA 2007 104: 19649-54.

6 Biederman J, Mick E, Faraone SV. Age-dependent decline of symptoms of attention deficit hyperactivity disorder: impact of remission definition and symptom type. Am J Psychiatry 2000; 157: 816-8.

7 Carver AC, Livesey DJ, Charles M. Age related changes in inhibitory control as measured by stop signal task performance. Int J Neurosci 2001; 107: 43-61

8 McAlonan GM, Cheung V, Cheung C, Chua SE, Murphy DG, Suckling J, Tai KS, Yip LKC, Leung P, Ho TP. Mapping brain structure in attention deficithyperactivity disorder: a voxel-based MRI study of regional grey and white matter volume. Psychiatry Res 2007; 154: 171-80.

9 Wechsler, D. Wechsler Intelligence Scale for Children (3rd edn) (WISC-III). Psychological Corporation, 1992.

10 Ho TP, Leung PW, Lee CC, Tang CP, Hung SF, Kwong SL, Lucas CP, Lieh-Mak F, Shaffer D. Test-retest reliability of the Chinese version of the Diagnostic Interview Schedule for Children-Version 4 (DISC-IV). J Child Psychol Psychiatry 2005; 46: 1135-8.

11 Tannock R, Schachar RJ, Carr RP, Chajczyk D, Logan GD. Effects of methylphenidate on inhibitory control in hyperactive children. J Abnorm Child Psychol 1989; 17: 473-91.

12 Pallant J. SPSS Survival Manual. A Step by Step Guide to Data Analysis Using SPSS: pp. 126-9. Open University Press, 2001.

13 Overmeyer S, Bullmore ET, Suckling J, Simmons A, Williams SC, Santosh PJ, Taylor E. Distributed grey and white matter deficits in hyperkinetic disorder: MRI evidence for anatomical abnormality in an attentional network. Psycho Med 2001; 31: 1425-35.

14 Castellanos FX, Giedd JN, Eckburg P, Marsh WL, Vaituzis AC, Kaysen D, Hamburger SD, Rapoport JL. Quantitative morphology of the caudate nucleus in attention deficit hyperactivity disorder. Am J Psychiatry 1994; 151: 1791-6.

15 Seidman L, Valera EM, Makris N, Monuteaux MC, Boriel DL, Kelkar K, Kennedy DN, Caviness VS, Bush G, Aleaedi M, Faraone SV, Bierderman J. Dorsolateral prefrontal and anterior cingulate cortex volumetric abnormalities in adults with attention-deficit/hyperactivity disorder identified by magnetic resonance imaging. Biol Psychiatry 2006; 60: 1071-80.

16 Sowell ER, Thompson PM, Welcome SE, Henkenius AL, Toga AW, Peterson BS Cortical abnormalities in children and adolescents with attention-deficit hyperactivity disorder. Lancet 2003; 362: 1699-707.

17 Mackie S, Shaw P, Lenroot R, Pierson R, Greenstein DK, Nugent TF, Sharp WS Giedd JN, Rapoport JL. Cerebellar development and clinical outcome in attention deficit hyperactivity disorder. Am J Psychiatry 2007; 164: 647-55.

18 Bush G, Valera EM, Seidman L. Functional neuroimaging of attention-deficit/ hyperactivity disorder: a review and suggested future directions. Biol Psychiatry 2005; 57: 1273-84

19 Tamm L, Menon V, Ringel J, Reiss AL. Event-related FMRI evidence of frontotemporal involvement in aberrant response inhibition and task switching in attention-deficit/hyperactivity disorder. J Am Acad Child Adolesc Psychiatry 2004; 43: 1430-40.

20 Rubia K, Overmeyer S, Taylor E, Brammer M, Williams SC, Simmons A, Bullmore ET. Hypofrontality in attention deficit hyperactivity disorder during higher-order motor control: a study with functional MRI. Am J Psychiatry 1999; 156: 891-6.

21 Schulz KP, Fan J, Tang CY, Newcorn JH, Buchsbaum MS, Cheung AM, Halperin JM. Response inhibition in adolescents diagnosed with attention deficit hyperactivity disorder during childhood: an event-related FMRI study. Am J Psychiatry 2004; 161: 1650-7.
22 Dickstein SG, Bannon K, Castellanos FX, Milham MP. The neural correlates of attention deficit hyperactivity disorder: an ALE meta-analysis. J Child Psychol Psychiatry 2006; 47: 1051-62.

23 Casey BJ, Castellanos FX, Giedd JN, Marsh WL, Hamburger SD, Schubert AB, VausS YC, Vaituzis AC, Dickstein DP, Sarfatti SE, Rapoport JL. Implication of right frontostriatal circuitry in response inhibition and attention-deficit/ hyperactivity disorder. J Am Acad Child Adolesc Psychiatry 1997; 36: 374-83.

24 Aron AR, Dowson JH, Sahakian BJ, Robbins TW. Methylphenidate improves response inhibition in adults with attention-deficit/hyperactivity disorder. Biol Psychiatry 2003; 54: 1465-8.

25 Aron AR, Poldrack RA. Cortical and subcortical contributions to Stop signal response inhibition: role of the subthalamic nucleus. J Neurosci 2006; 26 : 2424-33.

26 Clark L, Blackwell AD, Aron AR, Turner DC, Dowson J, Robbins TW, Sahakian BJ. Association between response inhibition and working memory in adult ADHD: a link to right frontal cortex pathology? Biol Psychiatry 2007; 61: 1395-401.

27 Middleton FA, Strick PL. Basal ganglia and cerebellar loops: motor and cognitive circuits. Brain Res 2000; 31: 236-50.

28 Middleton FA, Strick PL. Basal ganglia and cerebellar output influences nonmotor function. Mol Psychiatry 1996; 1: 429-33.

29 Nosarti C, Rubia K, Smith AB, Frearson S, Williams SC, Rifkin L, Murray RM. Altered functional neuroanatomy of response inhibition in adolescent males who were born very preterm. Dev Med Child Neurol 2006; 48: 265-71.

30 Vink M, Ramsey NF, Raemaekers M, Kahn RS. Striatal dysfunction in schizophrenia and unaffected relatives. Biol Psychiatry 2006; 60: 32-9.

31 Gothelf D, Hoeft F, Hinard C, Hallmayer JF, Stoecker JVD, Antonarakis SE, Morris MA, Reiss AL. Abnormal cortical activation during response inhibition in 22q11.2 deletion syndrome. Hum Brain Mapp 2007; 28: 533-42.

32 Nigg JT. Is ADHD a disinhibitory disorder? Psychol Bull 2001; 127: 571-98.

33 Slusarek M, Velling S, Bunk D, Eggers C. Motivational effects on inhibitory control in children with ADHD. J Am Acad Child Adolesc Psychiatry 2001; 40 355-63.

34 Gray JA. Behavioural and neural-system analyses of the actions of anxiolytic drugs. Pharmacol Biochem Behav 1988; 29: 767-9.

35 Quay HC. Inhibition and attention deficit hyperactivity disorder. J Abnorm Child Psychol 1997; 25: 7-13.

36 Tripp G, Alsop B. Sensitivity to reward frequency in boys with attention deficit hyperactivity disorder. J Clin Child Psychol 1999; 28: 366-75.

37 Luman M, Oosterlaan J, Sergeant JA. The impact of reinforcement contingencies on AD/HD: a review and theoretical appraisal. Clin Psychol Rev 2005; 25: 183-213.

38 Williams ZM, Bush G, Rauch SL, Cosgrove GR, Eskandar EN. Human anterior cingulate neurons and the integration of monetary reward with motor responses. Nat Neurosci 2004; 7: 1370-5.

39 Bush G, Luu P, Posner MI. Cognitive and emotional influences in anterior cingulate cortex. Trends Cogn Sci 2000; 4: 215-22.

40 McAlonan GM, Cheung V, cheung C, suckling J, Lam GY, Tai KS, Yip L, Murphy DGM, Chua SE. Mapping the brain in autism. A voxel-based MRI study of volumetric differences and intercorrelations in autism. Brain 2005; 128: $268-76$.

41 Barbas $\mathrm{H}$. Connections underlying the synthesis of cognition, memory, and emotion in primate prefrontal cortices. Brain Res Bull 2000; 52: 319-30.

42 Swanson JM, Flodman P, Kennedy J, Spence MA, Moyzis R, Schuck S, Murias M, Moriarity J, Barr C, Smith M, Posner M. Dopamine genes and ADHD. Neurosci Biobehav Rev 2000; 24: 21-5.

43 Giedd JN, Blumenthal J, Jeffries NO, Castellanos FX, Liu H, Zijdenbos A, Paus T, Evans AC, Rapoport JL. Brain development during childhood and adolescence: a longitudinal MRI study. Nat Neurosci 1999; 2: 861-3.

44 Castellanos FX, Lee PP, Sharp W, Jeffries NO, Greenstein DK, Clasen LS, Blumenthal JD, James RS, Ebens CL, Walter JM, Zijdenbos A, Evans AC, Giedd JN, Rapoport JL. Developmental trajectories of brain volume abnormalities in children and adolescents with attention-deficit/hyperactivity disorder. JAMA 2002; 288: 1740-8.

45 Rosa-Neto P, Lou HC, Cumming P, Pryds O, Karrebaek H, Lunding J, Giedd A. Methylphenidate-evoked changes in striatal dopamine correlate with inattention and impulsivity in adolescents with attention deficit hyperactivity disorder. Neurolmage 2005; 25: 868-76. 